\title{
COMPARISON OF BALLOONING MODE STABILITY PROPERTIES OF TOKAMAKS WITH CIRCULAR AND ELLIPTIC CROSS SECTIONS WITH THE SAME POLOIDAL FLUX
}

\author{
A. Miller, J. Manickam, and J. L. Johnson \\ Princeton Plasma Physics Laboratory, Princeton University, Princeton, New Jersey 08543

\begin{abstract}
The MHD ballooning mode stability limits for tokamak configurations with different cross section shapes but the same total poloidal flux are surprisingly similar.
\end{abstract}

PPPL- -2639

DE89 016955

\section{DISCLAIMER}

This report was prepared as an acoount of work sponsored by in abency of the United States Governmeat. Neither the Uaited States Government nor any ascacy theroof, sor aby of their Government. Neither the Uanty express of implied, or assumes any kgal liability of respontiemployech, makes any warranty, express of implied, of any information, oppatatus, product, of

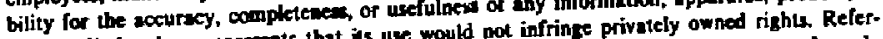
proces disclosed, ox represents that ins use would noes inf or service by trade name, irademark, ence herein to any specific commercial product, process, of service by trade name, irad recom-

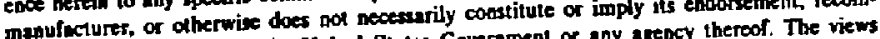
meadntion, or Pavoriog by the United States Goverament of any agency thereof. The the and opinions of euthors expresued berein do not

United Stales Government or any asency thereor. 


\section{INTRODUCTION}

The desire to confine high plasma pressures in tokamak reactors, while using only moderately high plasma currents, has provided an incentive to operate in the second stable region for ballooning modes [1-8]. The effects of configuration shape on this problem are important. It has generally been assumed that a tokamak with an elliptic cross section could have a better chance of getting into the second stability region for ballooning modes than one with a circular cross section since it lends itself to operation with higher $q$-values. However. ellipticity by itself is destabilizing, so that a quantitative study should be made to assess the relative importance of these two effects. The difficulty in this type of comparison is that the equilibria associated with the different configurations depend sensitively on many plasma parameters so that the results are strongly determined by the assumptions of what should be kept fixed. In this work we compare systems in which the poloidal flux between the magnetic axis and the plasma surface is kept fixed. This would appear to be a reasonable comparison since this flux is a measure of the effective poloidal field in the plasma. We also hold $q_{0}$, the safety factor at the magnetic axis, fixed. This arbitrary choice should make the results as insensitive to the behavior of the plasma parameters near the magnetic axis as possible. The fixed poloidal flux constraint then makes it impossible to hold $q_{\text {edge }}$ fixed as we change the shape of the plasma. Since the shape of the current profile is strongly dependent on the $q$-profile, we decided that it would make sense to fix the shape of the toroidal field function $g(\psi)$ at zero $\langle\beta\rangle$ to establish our base equilibtia for the different configurations, rather than to prescribe the shape of the safety factor $q(\psi)$.

We introduce our model in the next section. Our results for high-n ballooning modes are given in Sect. 3 and fot low-n kink modes in Sect. 4. Since the first and second stability regions are not connected for the configurations that we studied, we have considered the possibility of modifying one of them to get directly into the second stable regime. This is discussed in Sect. 5. We conclude with a few comments in Sect. 6.

\section{PLASMA MODEL}

We carried through the comparison with three sets of cases, first treating a series of equilibria with a circular plasma cross section, then a series with an elliptical cross section, and then one with a standard $D$-shape. In these cases we used the same pressure distribution,

$$
p(\psi)=p_{0}(1-\psi)^{\circ}
$$

with $\alpha=2.0$. We prescribe a toroidal field function

$$
g(\psi)=1-g_{p}(1-\psi)^{\top}
$$

with $\gamma$ and $g_{p}$ adjusted to get the correct value of $q_{0}$ and $\left(\Psi_{\text {edge }}-\Psi_{0}\right)$. Here

$$
\psi=\frac{\left(\Psi-\Psi_{0}\right)}{\left(\Psi_{\text {edge }}-\Psi_{0}\right)}
$$


with $\Psi$ the poloidal flux. We prescribe the shape of the plasma surface to be

$$
\begin{gathered}
R=R_{0}+a \cos (\theta+\delta \sin \theta), \\
Z=\kappa a \sin \theta .
\end{gathered}
$$

We set the aspect ratio $R_{0} / a$ equal to 5 . The ellipticity of the configuration is set by $\kappa$ and the triangularity by $\delta$.

We settled on a value of $\left(\Psi_{\text {edge }}-\Psi_{0}\right) \approx 0.0051$ by making a $\langle\beta\rangle=0 \%$ run for a case with a circulac cross section, adjusting the values of $\gamma$ and $g_{p}$ in $\mathrm{Eq} .(2)$ to be $\gamma=2.80, g_{p}=0.983$, to get $q_{0}=2.15$ and $q_{\text {edge }}=7.93$. We then adjusted $\gamma=3.30$ and $g_{p}=0.975$ for the $\kappa=1.4$, $\delta=0$ elliptical case to recover the same poloidal fux $\left(\Psi_{\text {edse }}-\Psi_{0}\right)$ and the same axis safety factor $q_{0}=2.16$ for $\langle\beta\rangle=0$. This led to an edge safety factor $q_{e d g e}=14.43$. We did the same for a $D$-shaped case with $\kappa=1.4, \delta=0.5 ; \gamma=3.17, g_{p}=0.987, q_{0}=2.14, q_{\text {edse }}=17.37$. We then ran a series of $q$-conserving cases to get a set of equilibria with increasing $\langle\beta\rangle$ for each of the configurations. The value of $\left(\Psi_{\text {edee }}-\Psi_{0}\right)$ remained constant, within $3 \%$, as we increased $\langle\beta\rangle$ for all of the cases and no discernable discontinuity in the toroidal current at the plasma boundary was introduced by this procedure. We examined the high- $n$ ballooning mode stability properties for each of the equilibria. The shapes of the magnetic surfaces for these configurations at a $\langle\beta\rangle$-value just above where one enters the second stable region and the corresponding $q$ and pressure profiles are shown in Figs. 1 and 2.

\section{BALLOONING MODE RESULTS}

\section{3.a. Circular Case}

Our measure of the growth rate of the most unstable ballooning mode is given as a function of $\langle\beta\rangle$ in Fig. 3 and as a function of $\epsilon \beta_{p}$ in Fig. 4. Instability sets in at $\langle\beta\rangle \approx 0.22 \%$, $\epsilon \beta_{\text {potoidal }} \approx 0.43$. The regions in the plasma that are unstable for different values of $\langle\beta\rangle$ are shown in Fig. 5a. The point in the middle denotes the surface with the fastest growing mode. The modes become weaker and more confined towards the outside as $\langle\beta\rangle$ is increased. This configuration reaches the second stable regime at $\langle\beta\rangle \approx 1.17 \%, \epsilon \beta_{\text {poloidel }} \approx 0.96$.

\section{3.b. Elliptical Case}

The results for the elliptical cross section are also given in Figs. 3 and 4 . The growth rates of the modes do not differ much from those of the circular case. In this case the first stable region ends near $\langle\beta\rangle \approx 0.22 \%, \epsilon \beta_{\text {poloidal }} \approx 0.80$. The second stability regime is reached at $\langle\beta\rangle \approx 1.0 \%, \epsilon \beta_{\text {poloide }} \approx 1.4$. The unstable regions are shown in Fig. 5b. Again, the location of the unstable surfaces shifts outward as $\langle\beta\rangle$ is increased.

\section{3.c. D-shape case}

The growth rates for a $D$-shaped cross section with $\kappa=1.4$ and $\delta=0.5$ are also shown in Figs. 3 and 4 , and the regions of instability in Fig. $5 \mathrm{c}$. In this case the unstable region 
is bounded between $\{\beta\} \approx 0.21 \%, \epsilon \beta_{\text {poloidal }} \approx 0.66$, and $\beta \approx 0.82 \%, \epsilon \beta_{\text {poloidal }} \approx 1.23$. In this case there is a smaller shift of the region of instability towards the outside as $\langle\beta\rangle$ is increased than in the other cases.

\section{LOW- $n$ INSTABILITIES}

For each of the cases, we picked the equilibrium that had the lowest $\langle\beta\rangle$ value in the second stable ballooning region and looked at its low- $n$ stability properties. Both the circular and elliptical shaped cases are unstable with respect to the $n=1$ free-boundary kink. The eigenfunctions for these two cases are given in Figs. 6 and 7 . The modes have a lot of structure and are very nonlocal. Conducting walls with the same shape as the plasma surface stabilize these modes, stability being obtained with $b / a \sim 0.25$, where $a$ is the distance from the magnetic axis to the plasma surface on a line directed outwards from the axis of the system and $b$ is the distance outwards from the plasma surface to the wall. The $D$-shaped case is stable with respect to these low-n modes for $(\beta)$ near the onset of ballooning second stability. However, at lower values of $\beta$ where the $D$-shaped configurations were strongly ballooning unstable, a low-n global instability was found. The instability, shown in Fig. 8 , is an 'infernal' mode, driven primarily by the interaction of pressure gradients with magnetic field line curvature, and has a much smaller growth rate than the kinks found in the other configurations. It can only be stabilized by placing a conducting wall at the plasma surface.

\section{DIRECT APPROACH TO SECOND STABILITY}

The fact that second stability can be achieved at reasonable plasma parameters even for simple configurations with circular cross sections makes it useful to ask how one could achieve direct stable access to this regime. Since the purpose of our investigation was to investigate the effects of configuration shaping rather than to propose specific experiments, we have done little work in this direction. We looked at several circular cross section configurations with $\gamma$ and $g_{p}$ adjusted to raise go, keeping $\sigma_{s d r e}$ fixed. Extrapolation of these indicated that the critical $\beta$-values for departure from the first stability regime and entry into the second should coalesce at $\langle\beta\rangle \approx 0.2 \%$ when $q_{0} \approx 5.5$ if the shape of the pressure distribution is not optimized. Since this occurs at fairly low pressure, it should be possible to use a current drive technique to obtain this profile shaping in order to enter the second stable regime and then peal: the distributions. The task thould actually be much easier if the profiles are more carefully adjusted.

\section{i. DISCUSSION}

The results for the calculation of ballooning modes are summarized in Figs. 3 and 4. The stability properties of these differently shaped plasmas are surprisingly similar. We see little difference between the locations of the unstable modes or of the magnitude of the eigenvalue for the most unstable mode for cases with circular or elliptical cross sections. Even the values of the parameter used to represent the pressure at the edges of the unstable region are similar. The curves for a $D$-shape configuration are qualitatively similar. We believe that the reduced shift of the unstable region towards the outside for this case, as 
observed in a comparison of Fig. 5c with Fig. 5a or 5b, is associated with a difference in the shape of the $q$-profile and could be modified easily by adjusting the shape of $p(\psi)$.

We found the behavior of the low-n modes to be more surprising. The instabilities observed in systems with circular or elliptic cross sections at the onset of second stability look like ordinary current-driven free boundary modes. Since the value of $q_{\text {edge }}$ is significantly higher in the elliptic case than in the circular one, it would be reasonable to expect to find a lower growth rate in this case. The fact that this is not observed provides one of many illustrations of the sensitivity of the MHD stability properties of tokamaks to the exaci plasma profiles. We see no sign of a low- $n$ instability near the onset of second stability in our $D$-shaped model. Since the growth rates for these kink modes decrease rapidly with decreasing $\langle\beta\rangle$, it is reasonable to conjecture that an instability would set in even in this case as this parameter is increased. As is illustrated in Fig. 8, we can find much weaker pressure-driven 'infernal' modes at lower values of $\langle\beta\rangle$ where the Shafranov shift has not produced a deep enough well to provide sufficient stabilization. We found that conducting surfaces near the plasma edge can control all of these low-n modes.

The possibility of using current drive or bootstrap techniques to operate with $q_{0}>1$ should make operation of tokamaks in the second stable region possible even with little or no configuration shaping. The ease of generating interesting equilibria is tied to the plasma shape. If the amount of auxiliary heating that is available provides the limiting effect so that the value of $\langle\beta\rangle$ at which the second stable region is entered is most important, the $D$-shaped plasma looks most encouraging. On the other hand, if the problem is primarily one of maintaining an equilibrium so that the value of $\epsilon \beta_{p}$ or the size of the Shafranov shift is the limiting factor, the circular cross section model appears to be very reasonable. It is worth noting that the second stability region can be aproached and entered at relatively small values of $(\beta)$ so that existing devices should be capable of investigating the behavior of plasmas in this regime.

\section{ACKNOWLEDGMENTS}

We are indebted to Dr. H. P. Furth for suggesting this problem and for providing valuable insight and comments. Drs. M. S. Chance, D. A. Monticello, and N. Pomphrey also contributed to the effort and to our understanding. Dr. Pomphrey's assistance in the early stages of this work was extremely useful. The work was supported by the US Department of Energy under Contract No. DE-AC02-76CH03073 with Princeton University. 


\section{REFERENCES}

[1] Mikhailovskii, A. B., and Shafranov, V. D., Sov. Phys.-JETP, 39 (1974) 88.

[2] Sykes, A., and Turner, M. F., in Controlled Fusion and Plasma Physics (Proc. 9th European Conf., Oxford, 1979) UKAEA, Culham Lab., Abingdon (1979) p. 161.

[3] Coppi, B., Comments in Plasma Physics 6 (1981) 109.

[4] Grimm, R. C. et al., Nuclear Fusion 25 (1985) 805.

[5] Chance, M. S., in Theory of Fusion Plasmas (Proc. Varenna Workshop, Varenna, Italy, September, 1987).

[6] Bonoli, P. T., Porkolab, M., Takase, Y., and Knowlton, S. K., Nuclear Fusion 28 (1988) 991.

[7] Naitou, H., and Yamazaki, K., Nuclear Fusion 28 (1988) 1751.

[8] Sabbagh, S. A., Hughes, M. H., Phillips, M. W., Todd, A. M. M., and Navratil, G. A., Nuclear Fusion 29 (1989) 423.

\section{FIGURE CAPTIONS}

Fig. 1. Shapes of magnetic flux surfaces for equilibria in the second stability region: (a) Circular cross section, $\langle\beta\rangle=1.11$; (b) Elliptical cross section, $\langle\beta\rangle=1.03$; (c) $D$-shaped cross section, $\langle\beta\rangle=0.80$.

Fig. 2. Pressure and $q$ profiles for the configurations of Fig. 1: (a) $q(\Psi)$ for circular cross section; (b) $q(\Psi)$ for elliptic cross section; (c) $q(\Psi)$ for $D$-shaped cross section; (d) $p(\Psi)$ for all cross sections.

Fig. 3. Ballooning mode eigenvalue as a function of $\langle\beta\rangle$.

Fig. 4. Ballooning mode eigenvalue as a function of $\epsilon \beta_{p}$.

Fig. 5. Ballooning mode unstable surfaces for different values of $\langle\beta\rangle$ for tokamaks with $(a)$ a circular cross section, (b) an elliptic cross section, and (c) a $D$-shaped cross section. The central point denotes the surface with the largest eigenfunction.

Fig. 6. (a) Fourier components of $\xi_{\psi}$, the component of the instability eigenfunction perpendicular to the magnetic surfaces, fo: a free-boundary $n=1$ mode in a circular tokamak with $\langle\beta\rangle=1.11 \%$; (b) eigenfunction $\xi$. The growth rate of this mode, normalized to the time it would take a shear Alfvén wave to propagate actoss the minor radius is 1.7.

Fig. 7. Fourier components of $\xi_{\psi}$, the component of the instability eigenfunction perpendicular to the magnetic surfaces, for a free-boundary $n=1$ mode in an elliptic tokamak with $\langle\beta\rangle=1.03 \%$; (b) eigenfunction $\xi$. The growth rate of this mode, normalized to the time it would take a shear Alfvén wave to propagate across the minor radius is 2.0 .

Fig. 8. Fourier components of $\xi_{\psi}$, the component of the instability eigenfunction perpendicular to the magnetic surfaces, for a free-boundary $\Omega=1$ mode in a $D$-shaped tokamak with $\langle\beta\rangle=0.39 \%$; (b) eigenfunction $\xi$. The growth rate of this mode, normalized to the time it would take a shea. Alfvén wave to propagate across the minor radius is 0.14 . 
"99T0109
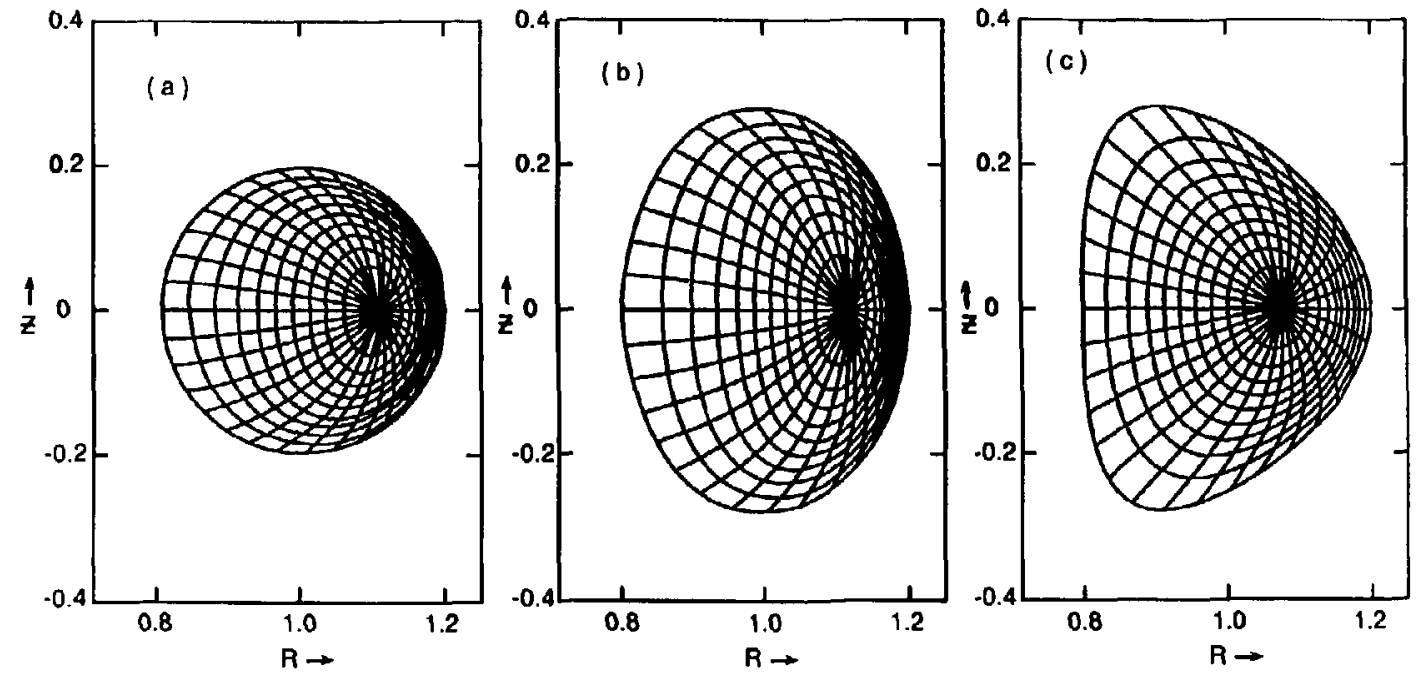

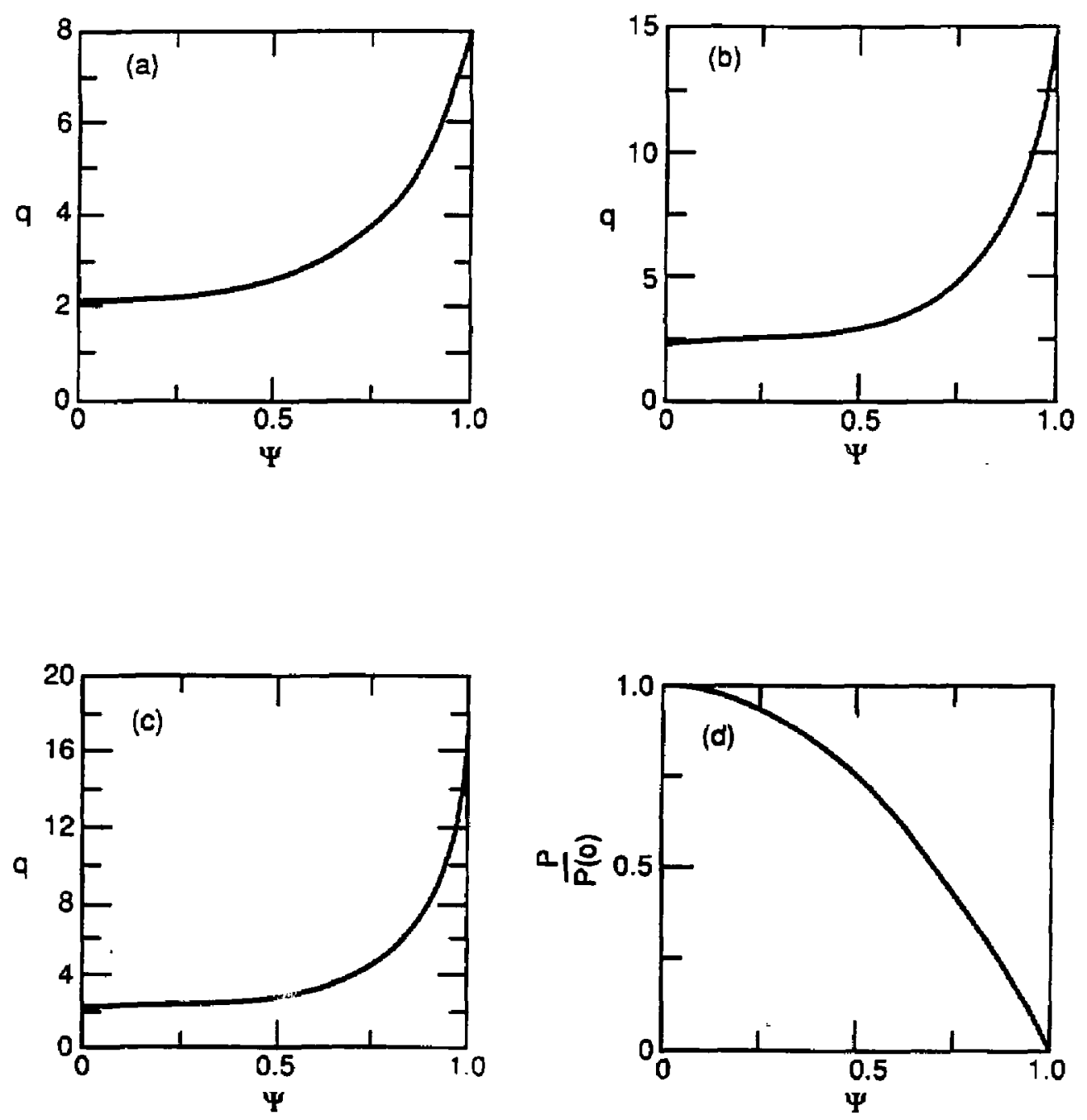

Fig. 2 


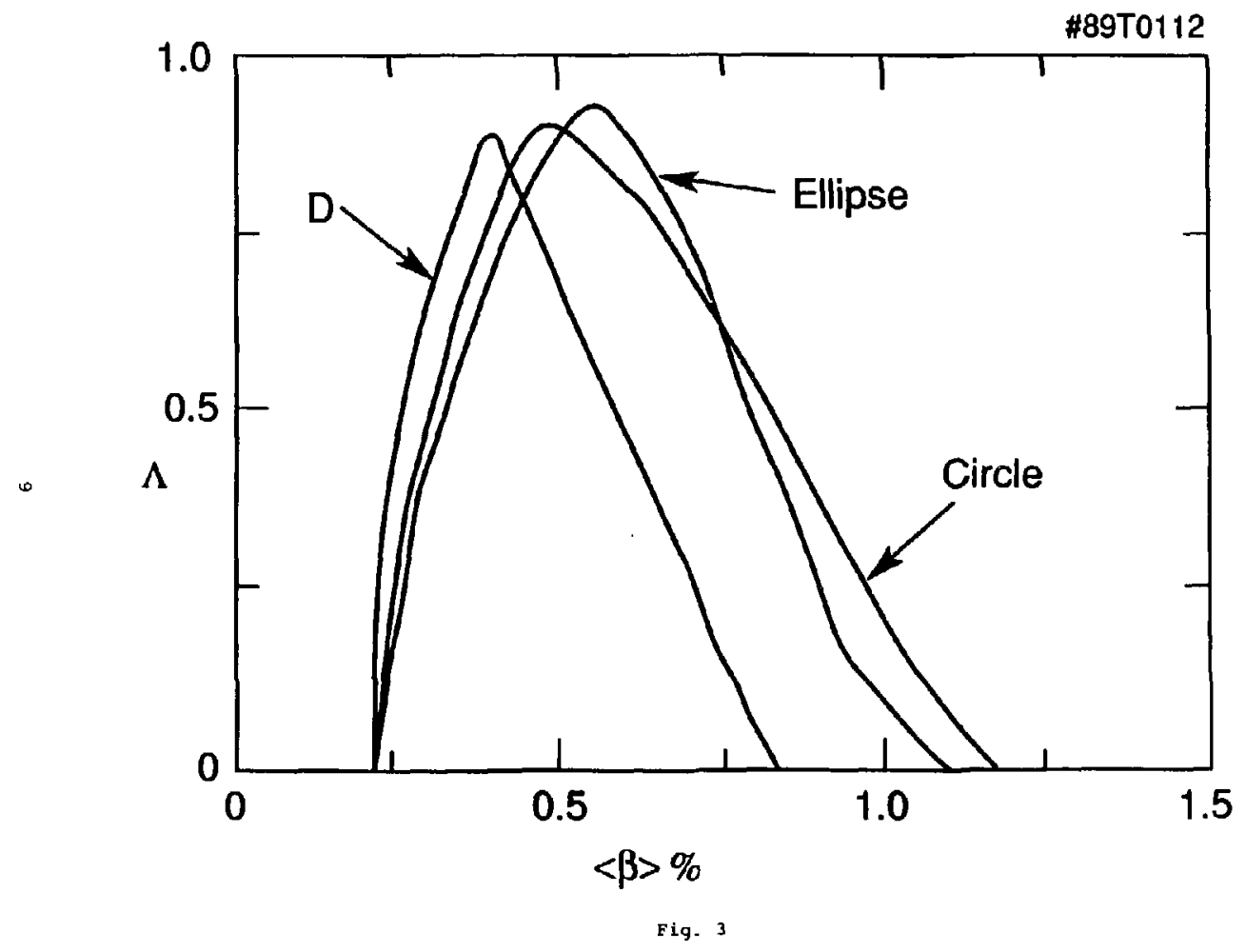


\#89T0111

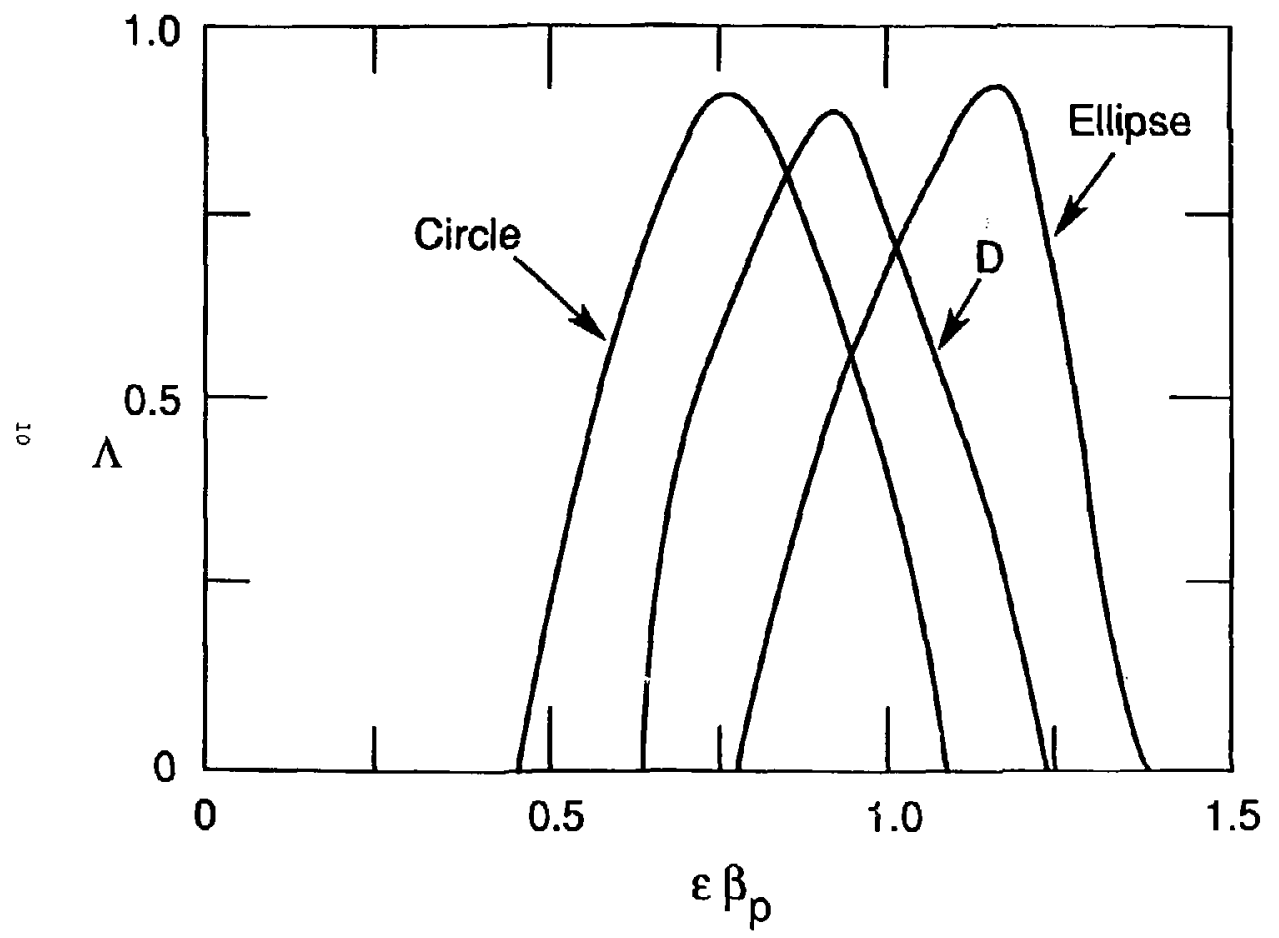

Fig, 4 


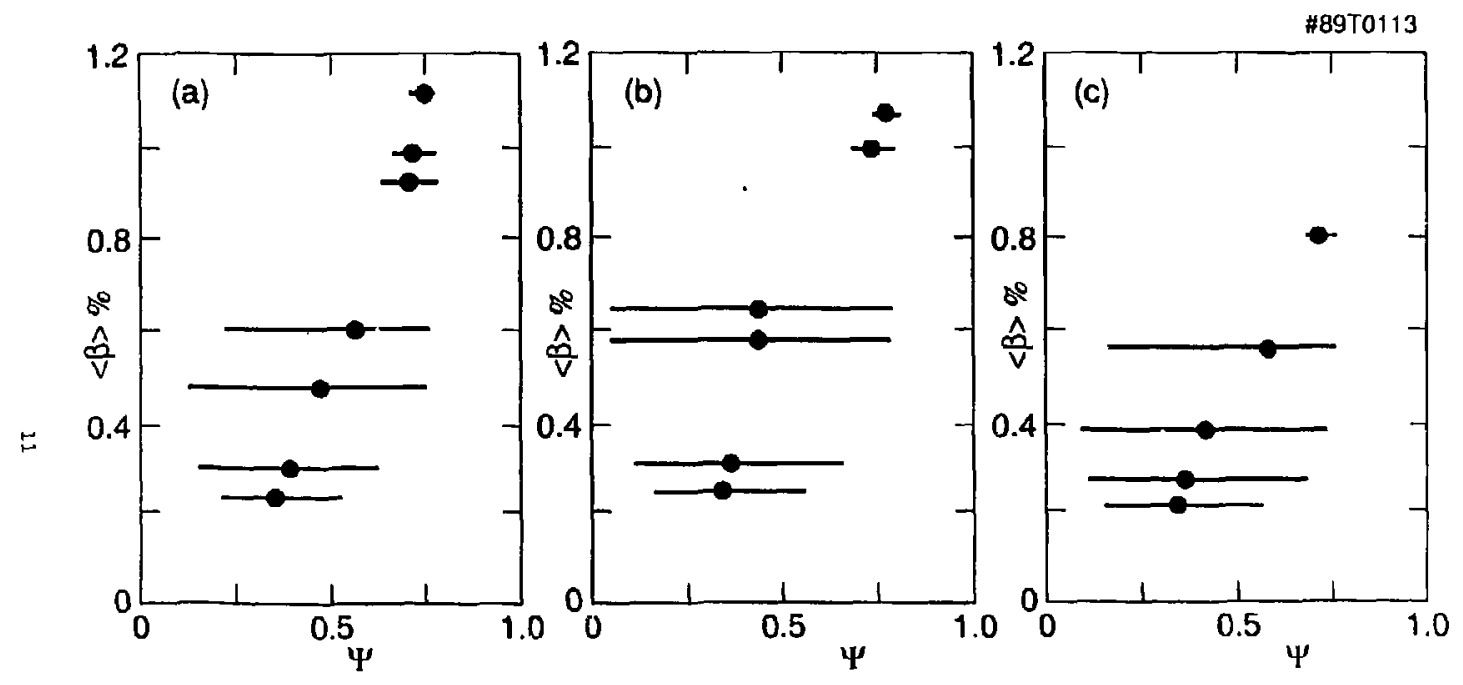

Fig. 5 

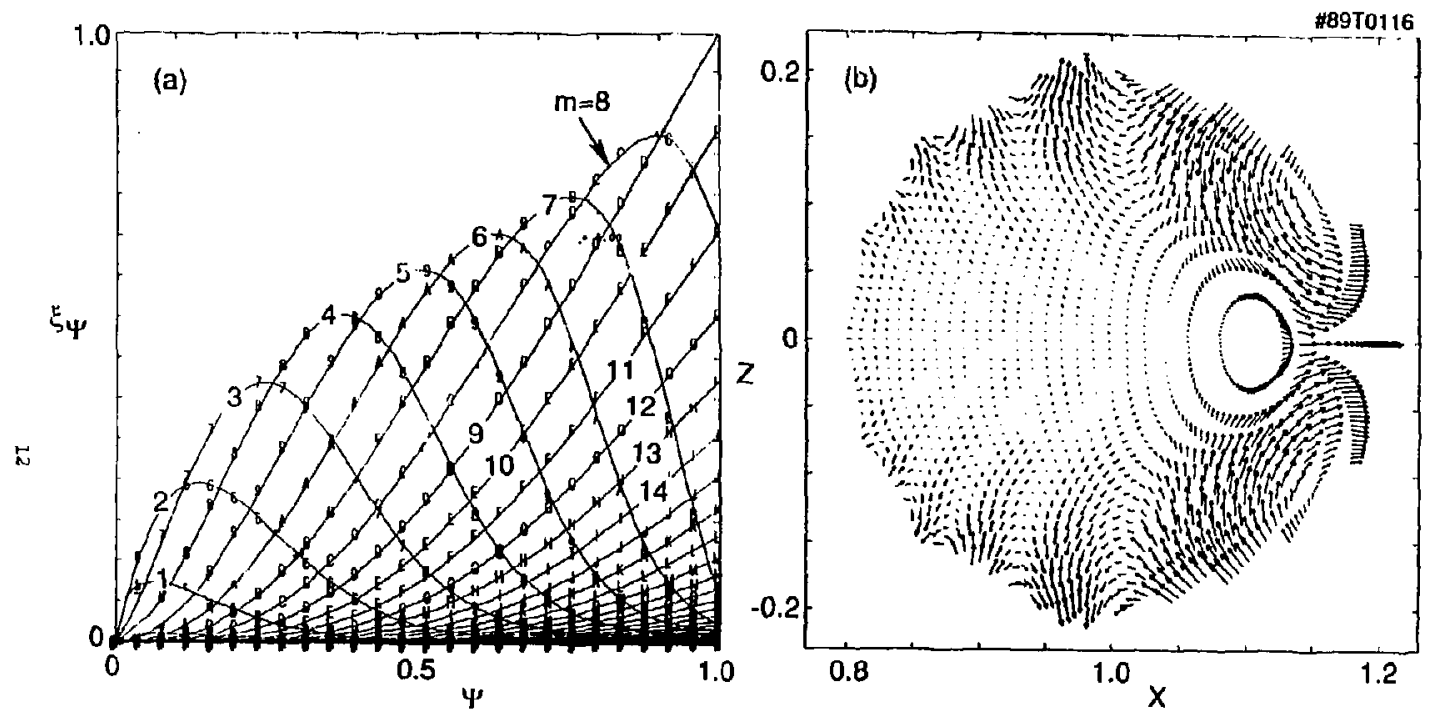

Fig. 6 

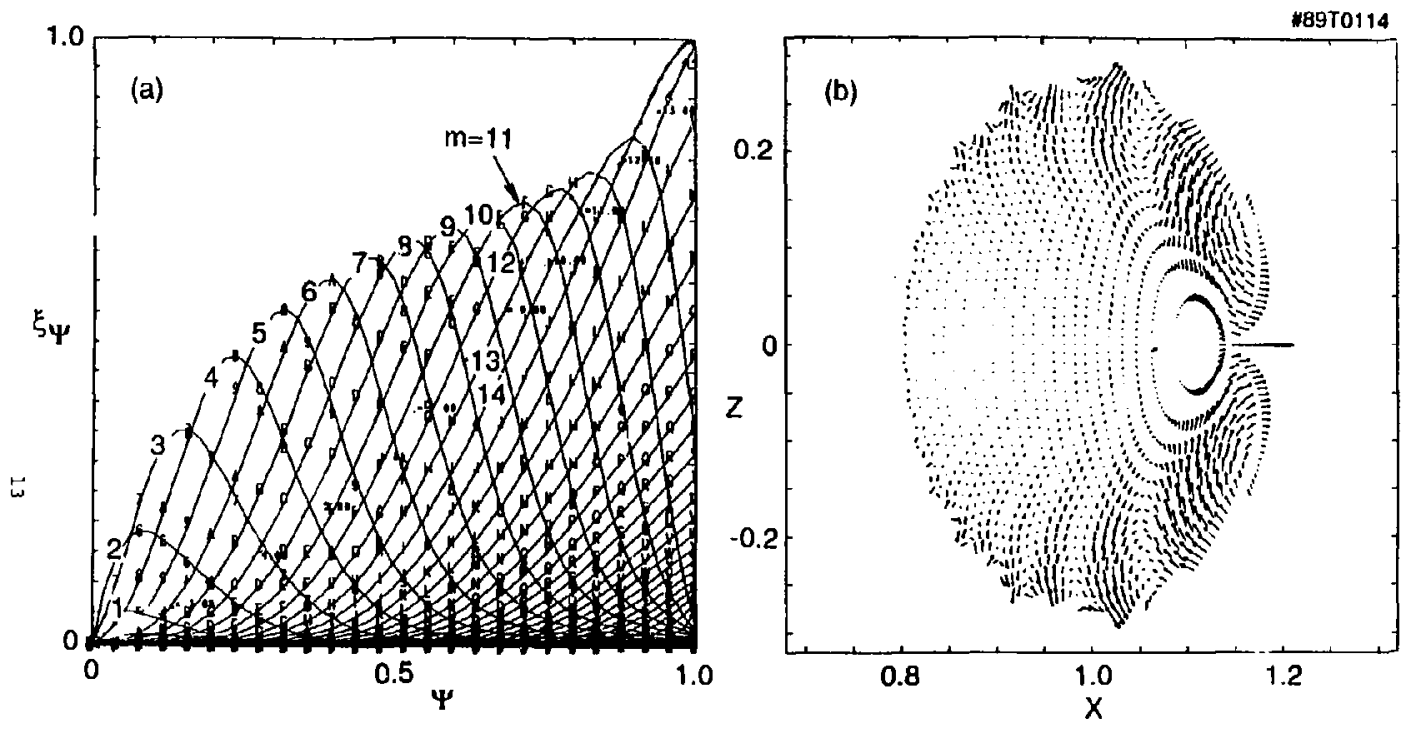

Fig. 7 

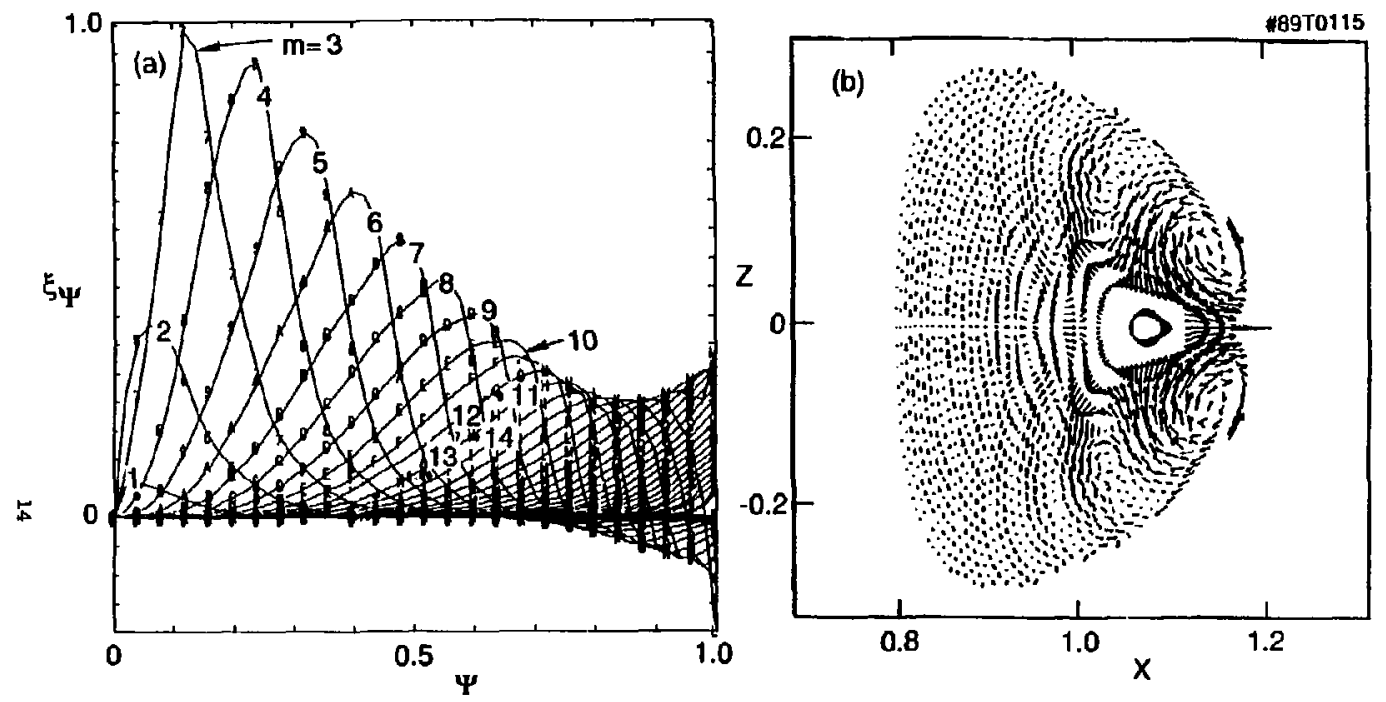

Fig. 8 
Dr. Frank J, Pooloni, Univ of wollongong, AUSTRALIA Prof. M.H. Brannan, Univ Sydnor, Australia Plasad Rasearch Lab., Austral ian Nat. Univ.., AuSTRALIA Prof, I.R. Jones, Filnders Univ, , AUSTRALIA Prof. F. Cap, Inst Theo Phys, NusTRIA

Prof. M. Haindler, Instut fur Theoretische Physik, AuSTRIA M. Coossens, Astronomisch Instrtuut, BELGIUM Ecole Royale Militaire, Leb de Phys Plasans, Belgivy Comission-Europan, Og-xil fusion Prog, eElgily Prof. R. Boweique, Ri jksuniversiteit Cent, Belgium Or. P.H. Sakunaka, instituto Eisica, BazIL Instituto De Pesquisus Especinsi-INPE, BRazIL Documents office, Atonie Energy of Canade Limitad, Cuwon Dr. M.P. Bechynski . MPB Technologies, Inc., Curuon Or. H.M. Skarsgard, University of Sasketchemen, CuMaA Or. H. Barnard, Universtty of British Columbia, cundA Prof. d. Toichmann, Univ. of Hontreal, cawon Prof. S.R. Sreenivasan, Universlty of Calgary, Cwaon Prol. Tudor w. Jonnston, IMPS-Enorgie, CAMDA Or. Bolton, Contre canadien'de fusion megnetique, cuman Or. C.R. Jenes, Univ. of Alberte, CAwan Or. Potar Lukec, Kommskeho univ, CzEChostovakia The Librorian, Culhe Lebioratory. ENcLNo The Librarian, Rutharford Appleton Loboratory, EMGLAND Hrs. S.A. Hutchinson, JET LIbrery, ENGLN

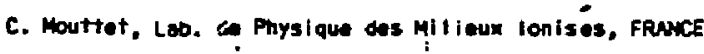
J. Radat, CEN/CNOARACHE - Bst 506, Fanice H. C. Rioni, Librarian, Univ. of lownind, GaEece or. Tou that, Acadery Bibliographic ser., Howg Kowg Proprint Library. Hungarien Academy of Sciences, MUwGaRr Dr. B. Das Gupta, Saha inst of Nuel. Phys., INDiA Dr. P. Kaw, Institutu for Plasan Aesearch, INDIA Dr. Philip Rosenau. Isreet Inst. of Toch, ISRAEL Librarion, Int'I Ctr Theo Phys, ITALY Prof. G. Fostagni, Istituto Gas Ionizzati Del CNR, ITALr Miss Clel ia De Polo, Assoc ElRATOH-ENEA, rTALY Dr. G. Grosso, Istituto di fisica del Plasma, ITALY Dr. H. Yanato, Toshibu Res 8 Dev, JAPAN
Prof. 1. Kovokad, Atomic Enargy Res. Instituto, JAPAN Prof. Kyoji Nishikawa, Univ of Hiroshima, JAPAN Director, Dept. Large Tokamak Ros. JAERI, JAPAN Prof. Satoshi Itoh, Kyushu Univarsity, JAPAN Research info Center, Magovo Univorsity, JAPAN Prof. S. Tanaka, Kyoto University, JAPAN Library, Kyoto University, JAPAN Prof, Nobuyuki Inoue, University of TOkyO, JAPAN S. Mori, JAERI, JAPAN

H. Jeong. Llorarian, Kores Advanced Energy Ras Inst, KOREA Prof. D.1. Chol. The Korea Adv, Inst of Sei \& Tech, KOREA Prot. B.S. Lilay, University of Walkato, NEW CEALAMD institute of Plaste Physics, PEOPLE'S REPU⿴L冂) of OHINA Librarian, Institute of Phys., PEOPLE'S REPUBLIC Of CHINA Library, Tsing tha Univarsity, PEOPLE'S REPU⿴囗十 IC OF CHINA 2. Li, Southwest Inst. Physies, PEOPLE'S REPUELIC of CHINA Prot, J.A.C. Cabral, Inst Superior Teenico, PORTUGAL Dr. Octavian Petrus, AL I CuzA University, ROwanIA Dr. Jas de Villiers, Fusion Studies, AEC, SO AFRICA Prof. M.A. Hellberg, University of Natal, SO AFRICA C.I.E.M.A.T., Fusion Div. Library, SPAIN Dr. Lennart Stenflo, Iniversity A: UMEA, SWEDEN Library. Royal Institute of Tech, SiwEEN Prof. Hans Withelasen, chalmars Univ of Tech, SWEDEN Centre Phys aes Plasmas, Ecol Polytech Fad, SwITzERLANo Bibl iotheak, Fom-Inst Voor Plasma-Fysica, THE METHERLNOS Matin Durgut, Midale East Technical University, TURKEY D. D.D. Ryutov, Siberian Acad Sci, USSR Or. G.A. El isenv, Kurchator Instifute, USSR Or. V.A. Glukhikh, Inst Electrophysical Apparatus, USSR Prof. 0.5. Padichenko, Inst, of Phys. \& Tech. USSR Dr. L.M. Kovrizhnykh, Institute of Gen. Physics, US\$R Huclear Res. Establ ishment, Julich Ltd., W. GERAANY Bibliothek, Inst. Fur Plasmalorsehung, W. GEPany Dr. K. Schindler, Ruhr-Univarsitat Gochum, W. GERouNr ASDEX Raading Am, cro Wagner, IPPMaxtlanck, H. EEfMANY Librarian, Max-Planck Institut, W. GEFMANY Prof. R.K. Jangev, Inst of Phys, Yugoslavia 